BRIEF REPORT

\title{
Child safety education and the world wide web: an evaluation of the content and quality of online resources
}

\author{
D Isaac, M D Cusimano, A Sherman, M Chipman
}

See end of article for authors' affiliations

......................

Correspondence to: Dr Michael Cusimano, Injury Prevention Research Centre, St. Michael's Hospital, 38 Shuter Street, Suite 2-018, Toronto, Ontario, M5B 1A6, Canada; injuryprevention@smh. toronto.on.ca
Injury Prevention 2004;10:59-61. doi: 10.1136/ip.2003.003327

The purpose of this study was to assess the content, quality, and type of internet resources available for safety education. Using 19 search engines with search strings targeting major forms of injury, identified resources were classified by audience group, accessibility, and authorship. Two independent reviewers rated each resource on the basis of its content and a set of quality criteria using a three point scale. Overall, $10(18.2 \%)$ resources were of highest quality, four (7.3\%) were intermediate, and 41 (74.5\%) were not recommended. Eighteen months after the original search, $67.3 \%$ of all resources and $90 \%$ of the highest quality resources were still on the internet. This study provides a methodology for evaluating child safety resources on the world wide web and demonstrates that most internet resources for safety education are of dubious quality. A rating system such as the one developed for this study may be used to identify valuable internet materials. l ternet use has risen dramatically in recent years, a trend estimated to be three times faster than that of television,

four times faster than personal computers, and nine times faster than radio. ${ }^{1}$ Parallel to this growth in the internet has been a growing recognition of the huge burden of injury worldwide. ${ }^{2}$ School teachers aided by public health professionals, parents, and community groups increasingly lead health education efforts and programming that depend on internet resources. ${ }^{34}$

Access to such a large and unregulated body of information, as exists on the internet, suggests a need for critical evaluation of health related internet resources. ${ }^{5}$ Although a number of studies have reviewed internet information for many different health conditions, ${ }^{6-8}$ there have been no similar evaluations of online injury prevention information. The purpose of this work was to assess the content, quality, and type of internet (web) resources that are available to supplement child safety education.

\section{METHODS}

\section{Search strategy}

Copernic 2001 Basic combined with Ask Jeeves, Overture, and Dogpile were used in July 2001 for the search strategy, with Microsoft Internet Explorer 5.5 as the web browsing software. Nineteen search engines were accessed; at the time of the search these included the top 16 search engines reported by Jupiter Media Metrix. ${ }^{9}$ Only the first 10 URLs were collected because we assumed that typical web users do not look beyond the first page of search engine. Non-English resources, resources that required payment, and resources that contained irrelevant information were excluded.

The websites were categorized by: (1) target audience; (2) the means of access to each resource; and (3) authorship.

\section{Evaluation criteria of material found}

Two raters independently evaluated the content and quality of each resource. Inter-rater reliability was assessed by percent agreement and Kendall's tau. The following process was used for evaluation:

\section{(A) Content assessment score}

Content checklists specific to each safety theme and audience group were developed. These were intended to represent the content an ideal resource would contain (table 1).

Each reviewer assessed the presence or absence of each content item in the resource. The percentage of total content checklist items present in the resource constituted its content assessment score.

Our initial version of the checklists was drawn from the content contained in the Think First for Kids injury prevention curriculum, ${ }^{10}$ which is a comprehensive, internationally used school based injury prevention program that corresponds with the health and safety curricular expectations of all the Canadian provinces, ${ }^{11}$ and the "Kid's Page" of the website of the United States Fire Administration. ${ }^{12}$ The initial checklists were supplemented by content items drawn from the first 15 resources included in the study to create a final comprehensive content checklist.

If a resource covered more than one safety theme, the theme that received the highest content assessment score determined the overall content rating of a resource.

(B) Quality assessment score

Quality criteria were drawn from those described by Worthen and Sanders, ${ }^{13}$ and the American Medical Association recommendations for websites. ${ }^{14}$ Upon completing our preliminary search strategy we felt that a more appropriate set of criteria should consider audience needs, and accommodate for the variable forms in which online information is presented. Teacher resources were therefore evaluated on criteria that considered their usefulness in teaching: clarity of the directions/lesson plan, level of engagement for children, number of outside materials required, references to source material, and currency (timeliness). Parent resources' criteria were more typical of those used for evaluating websites: readability, aesthetic appeal/organization, and currency. Child resources were evaluated on the same criteria as parent resources, adding the criteria of lack of advertisements and navigability, since child materials tended to spread their information out across several web pages. Each criterion was rated on a scale of 1 (lowest) to 3 (highest).

As a result of different criteria and weighting, child, teacher, and parent resources were scored for quality out of 13.5, 12, and 7.5 points, respectively. These scores were converted to percentages, called the quality assessment score. 
Table 1 A sample of two content checklists. A subjective assessment by two reviewers of whether each content item was present in the resource determined its content assessment score

\begin{tabular}{l} 
Violence and peaceful conflict resolution \\
\# Concept: child resources \\
1. Some variation of "stop, don't touch, leave, and get an adult" if a \\
gun is found \\
2. Talking is a better way of solving disputes than violence \\
3. Respecting others' differences and ideas \\
4. Ask an adult for help if a solution cannot be found \\
5. Importance of listening to others \\
6. Emphasis on the harm that violence and weapons can cause \\
\# Concept: parent resources \\
7. Same as child resources (1-6) \\
\# Concept: teacher resources \\
Same as child resources (1-6) \\
Water safety \\
\# Concept: child resources \\
1. Adult supervision is required \\
2. Learn how to swim \\
3. Check if the water is deep enough to dive \\
4. How to assist when someone else is in trouble \\
5. Do not panic if in trouble, and attempt to float (or conserve body \\
heat) \\
6. Check water for unseen hazards \\
7. Wear a life jacket for water activities (boating, skiing, etc), or if \\
8nable to swim \\
8. Follow posted safety rules, or directions of lifeguard \\
9. Swim in designated swimming areas \\
10. No horseplay/dangerous activities \\
\# Concept: parent resources \\
1. Supervise children \\
2. Make sure children learn to swim \\
3. Check if the water is deep enough to dive \\
4. Learn lifesaving skills (child cardiopulmonary resuscitation, etc) \\
5. Check water for unseen hazards before letting children go in \\
6. Set an example by wearing a life jacket for water activities \\
7. Teach children to wait for permission before going in the water, and \\
8. Do listen to the lifeguard \\
9. Encourage dangerous play, running on pool decks, diving in \\
कoff, locked) pools are inaccessible to children alone (that is, fenced \\
\# Concept: teacher resources \\
Same as child resources \\
\hline
\end{tabular}

\section{(C) Overall rating}

Content and quality assessment scores were converted into overall ratings of "poor", "fair", or "excellent". A "poor" rating was given for scores less than $50 \%$, a "fair" rating for scores of $50 \%$ to less than $75 \%$, and higher scores were deemed "excellent". In determining the overall content ratings, only the content assessment score from the main safety focus of a resource was considered. Inter-rater agreement was calculated for this categorical scale.

\section{RESULTS}

We identified a total of 55 internet accessible resources. We classified $19(34.5 \%)$ as child oriented resources, $25(45.5 \%)$ as parent oriented, and $11(20.0 \%)$ as teacher oriented. Nonprofit $(47.3 \%)$ and government authors $(27.3 \%)$ produced a majority of the resources.

The number of resources that addressed each safety theme, starting with the most common, was: bicycle safety $(\mathrm{n}=28)$, water safety $(n=24)$, car/seatbelt safety $(n=19)$, sports/ recreation safety $(n=15)$, bus safety $(n=14)$, pedestrian safety $(n=14)$, violence $(n=14)$, and fire safety $(n=12)$. Falls were included in the sports/recreation and pedestrian categories. Some resources discussed more than one safety theme, so these numbers do not add to the expected total of 55.
Fifty one of the 55 safety resources contained web page content, 13 resources contained content requiring an additional download, two resources required a print out, and five resources allowed for free postal mail delivery of some materials.

\section{Content ratings}

Four child resources $(21.1 \%)$, four parent resources $(16.0 \%)$, and four teacher resources (36.4\%) earned "excellent" ratings for content from both reviewers. The agreement between reviewers for the categorical poor, fair, and excellent ratings was $80.0 \%$, and Kendall's tau was 0.952 .

\section{Quality ratings}

Both reviewers gave "excellent" quality ratings to 10 child resources $(52.6 \%), 13$ parent resources $(52.0 \%)$, and six teacher resources $(54.5 \%)$. The associated agreement on these ratings was $69.1 \%$, with a Kendall's tau of 0.947 .

\section{Overall recommendations}

Ten $(18.2 \%)$ of the 55 resources were rated as "excellent" by both reviewers for content and quality. Four (7.3\%) resources fell short of this category because of one "fair" rating for either content or quality from one reviewer. Forty one resources $(74.5 \%)$ were rated "not recommended" because they received more than one "fair" (or worse) rating on content or quality.

\section{DISCUSSION}

Our study found that content-rich, high quality web resources to supplement child safety education exist, but are hidden among a larger number of less desirable resources. From our data, a teacher or parent searching for safety education resources encounters material of questionable content, completeness, or quality about $75 \%$ of the time. Similar results - that excellent online resources make up a minority of what is available-have been found in other studies of web based health information. ${ }^{6} 715$

There are several limitations to the generalizability of our results. First, as new information is added to the ever expanding and ephemeral world wide web, older information is being removed, relocated, or becomes otherwise unavailable. For example, Li et al and Pandolfini and Bonati found that only a fraction of sites remained accessible after a period of up to two years. ${ }^{6}{ }^{16}$ Our initial review was performed in July 2001 and two follow up "accessibility checks" were performed 12 months and 18 months later. While the initial review found 55 resources, the 12 month follow up search found 38 resources, and 18 months later there were 37 accessible resources. Parent resources were the most transient (declined from 25 to 15 over 18 months) while those that we rated as the best quality were most likely to persist after 18 months (90.0\% remaining versus $58.5 \%$ for those not recommended).

A second limitation of our study is that the quality criteria we define may not fully describe the quality of a safety education resource for child, teacher, or parent audiences. A consensus on the definition of a high quality website is needed before meaningful evaluations can be conducted.

Perhaps the most difficult aspect of using the world wide web is simply finding relevant documents. Although we chose not to document the large amount of unrelated information encountered in our search, wading through extraneous results is a major obstacle that web users must face when seeking injury prevention resources. The output from today's search engines often reveals little about the nature of the located documents. Users are frequently led to resources where the content does not correspond to the search query or intended audience, or the overall quality of 
the resource is questionable. This may be a result of search engines allowing companies to bid for prominent placements on search output screens, and consequently, the best, most relevant sites may not be seen. In our experience, brief descriptions provided by website authors for each of their links are often more helpful than the typical search engine output in determining the relevance of the linked document. Such links are often subjectively compiled by the website authors and are not rigorously evaluated. Before forming website links or using an online resource for safety education, we would encourage the use of rating systems such as the one we have developed to determine the value of the online document.

\section{Authors' affiliations}

D Isaac, A Sherman, Injury Prevention Research Centre, St Michael's Hospital, Toronto

M D Cusimano, Injury Prevention Research Centre and Division of Neurosurgery, St Michael's Hospital, University of Toronto, Toronto M Chipman, Injury Prevention Research Centre, St Michael's Hospital, Toronto and Department of Public Health Sciences, University of Toronto, Toronto

\section{REFERENCES}

1 Shields MK, Behrman RE. Children and computer technology: analysis and recommendations. Future Child 2000;10(2):4-30.

2 UNICEF. A league table of child deaths by injury in rich nations. Innocenti Report Card No 2. Florence: UNICEF Innocenti Research Centre, February 2001.

3 Iverson DC, Kolbe U. Evolution of the national disease prevention and health promotion strategy: establishing a role for the schools. J Sch Health

1983;53:294-302.
4 American Academy of Pediatrics. Committee on Public Education. Media education. Pediatrics 1999;104(2 pt 1):341-3.

5 Eysenbach G. Welcome to the Journal of Medical Internet Research (editorial). Journal of Medical Internet Research 1999;1:e5. URL: http://www.jmir.org/ 1999/1/e5/.

6 Li L, Irvin E, Guzmàn J, Bombardier C. Surfing for back pain patients: the nature and quality of back pain information on the internet. Spine $2001 ; 26: 545-57$.

7 Beredjiklian PK, Bozentka DJ, Steinberg DR, et al. Evaluating the source and content of orthopaedic information on the internet: the case of carpal tunnel syndrome. J Bone Joint Surg Am 2000;82:1540-3.

8 Impicciatore $\mathbf{P}$, Pandolfini $C$, Casella N, et al. Reliability of health information for the public on the world wide web: systematic survey of advice on managing fever in children at home. BMJ 1997;314:1875-9.

9 SearchEngineWatch.com. Jupiter Media Metrix search engine ratings. URL: http://www.searchenginewatch.com/reports/mediametrix.html (accessed 24 July 2001).

10 THINK FIRST CANADA Foundation and the Durham District School Board. TD THINK FIRST For Kids: "Discoverers"-grades 1, 2, 3. Toronto: THINK FIRST CANADA Foundation/Whitby: Durham District School Board, 2001.

11 Cusimano M, Rodriguez C, Ullrich D, et al. Meeting injury prevention curricular expectations: the Canadian experience. Proceedings of the 6th World Conference on Injury Prevention and Control. 12-15 May 2002. Montreal, Canada. Montreal: Les Presses de l'Université de Montréal, 2002.

12 US Fire Administration. Fire safety and education. Emmitsburg, MD: US Fire Administration. Available at: http://www.usfa.fema.gov/safety/safety.htm (accessed 21 June 2001).

13 Worthen BR, Sanders JR. Educational evaluation: alternative approaches and practical guidelines. White Plains, NY: Longman Inc, 1987:92-6.

14 Winker MA, Flanagin A, Chi-Lum B, et al. Guidelines for medical and health information sites on the internet: principles governing AMA web sites. American Medical Association. JAMA 2000;283:1600-6.

15 Berland GK, Elliott MN, Morales LS, et al. Health information on the internet: accessibility, quality, and readability in English and Spanish. JAMA 2001;285:2612-21.

16 Pandolfini C, Bonati M. Follow up of quality of public oriented health information on the world wide web: systematic re-evaluation. $B M J$ 2002;324:582-3.

CALENDAR

Lifesavers Conference: National Conference on Highway Safety Priorities. 28-30 March 2004.

San Diego, California. Details: www.lifesaversconference.org.

World Health Day. 7 April 2004. The theme is road safety.

2004 National Sexual Violence Prevention Conference. 25-28 May 2004. Los Angeles, California. Details: www.cdc.gov/ncipc/2004nsvpc.htm.

13th International Conference on Safe Communities. 2-4 June 2004. Prague, Czech Republic. Details: www.13safecomm.com.

2nd Conference on Public Health and War-related Injuries. 3-5 June 2004. The Role of Public Health in the Prevention of War-related Injury. Vienna. Details: www.cdc.gov/nceh/ierh/ Conference.htm

7th World Conference on Injury Prevention and Safety Promotion. 6-9 June 2004. Vienna. The major objectives of the conference are strengthening violence and injury prevention as an aspect of national public health policy and programs; producing synergy of the combined efforts of various violence and injury prevention disciplines; exchanging the most recent experiences in research and practice; and facilitating participation of experts from low income countries. Further information from www.safety2004.info. Details of the nine associated meetings can be found at www.safety2004.info/associated_meetings.php.

IRCOBI Conference: The Biomechanics of Impact. 21-24 September 2004. Graz, Austria. Details: www.ircobi.org. 